\title{
Victor Hugo, Lucrèce Borgia
}

\section{Lise Sabourin}

\section{(2) OpenEdition}

\section{Journals}

\section{Édition électronique}

URL : http://journals.openedition.org/studifrancesi/8977

DOI : 10.4000/studifrancesi.8977

ISSN : 2427-5856

\section{Éditeur}

Rosenberg \& Sellier

\section{Édition imprimée}

Date de publication : 1 octobre 2008

Pagination : 475-476

ISSN : 0039-2944

\section{Référence électronique}

Lise Sabourin, «Victor Hugo, Lucrèce Borgia », Studi Francesi [En ligne], 155 (LII | II) | 2008, mis en ligne le 30 novembre 2015, consulté le 10 janvier 2021. URL : http://journals.openedition.org/studifrancesi/ 8977 ; DOI : https://doi.org/10.4000/studifrancesi.8977

\section{Ce document a été généré automatiquement le 10 janvier 2021.}

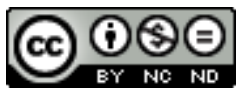

Studi Francesi è distribuita con Licenza Creative Commons Attribuzione - Non commerciale - Non opere derivate 4.0 Internazionale. 


\title{
Victor Hugo, Lucrèce Borgia
}

\author{
Lise Sabourin
}

\section{RÉFÉRENCE}

VICTOR HUGo, Lucrèce Borgia, édition de Clélia Anfray, Paris, Gallimard, 2007 («Folio

théâtre»), pp. 254.

1 Cette pièce à succès de 1833 est tombée quasiment dans l'indifférence aujourd'hui. Cela tient-il au caractère «innommable» de la Lucrèce Borgia de Hugo? Le dramaturge a effectivement poussé bien au-delà des faits historiques - son fils Gennaro est une invention littéraire - le matériau fourni par les Mémoires pour servir à l'histoire de César Borgia, tirant ces «Atrides du moyen âge» vers Phèdre et Médée en faisant d'une femme surtout instrumentalisée par sa famille une mère criminelle. Cette héroïne qui n'est pas sans rappeler la Marguerite de Bourgogne dumasienne de La Tour de Nesle, cas-limite de «difformité morale» comme Triboulet l'était physiquement dans Le Roi s'amuse, semble se souvenir d'Eschyle (on pense notamment à Ion, mais sans certitude sur l'inspiration hugolienne), mais aussi du malentendu tragique et ironique d'Edipe roi ou encore des drames shakespeariens.

2 Se rapprochant ainsi du genre tragique - héros mus par la fatalité, claustration spatiale, terreur et pitié cathartiques - Hugo, par son rire plus satanique que carnavalesque malgré le contexte médiéval, ne masque pas l'angoisse moderne du vide métaphysique. Son choix d'écriture en prose pose aussi la question du genre: sans doute dicté par le lieu populaire de la création, le Théâtre de la Porte Saint-Martin, il marque aussi le climat de suspicion que soulignent l'abondance des apartés et la rareté des monologues. Drame romantique et mélodrame, tragédie s'entrelacent, de l'aveu des contemporains qui y saisissent bien la volonté de l'auteur de lutter contre «l'arbitraire distinction des genres».

3 Hugo, dans le contexte politique et social très tendu de 1832 où il compose, transpose aussi complots, conspirations, insurrections et épidémie sur la tribune théâtrale: Gennaro, tout en restant chevalier à la destinée mythique plutôt que champion du 
peuple, manifeste par la mutilation initiale du nom de sa mère l'«orgia» profonde à laquelle est livré ce monde où il erre, mélancolique comme Hamlet, en quête d'un sens qui le détruira en même temps que ce qu'il dénonce.

4 Cécile ANFRAY, par son introduction (pp. 7-31), rappelle tous ces enjeux et ajoute, outre une chronologie hugolienne, un rappel historique sur le temps des Borgia en Italie, les variantes du texte de 1833 et 1882 , des indications bibliographiques et des notes, un dossier sur les représentations (pp. 219-227) selon le principe de cette collection «Folio théâtre». À la création, avec Mlle George et Frédérick Lemaître, Hugo se soucie attentivement de la mise en scène, mais aussi d'un décor et d'une musique assurant contrepoint sans illusion réaliste excessive. L'immédiateté des parodies et traductions atteste de l'ampleur du succès, persistant lors des reprises, épisodiques évidemment sous l'Empire, mais réussies en 1870, 1877 (avec Sarah Bernhardt) et 1881. La postérité en revanche reste réticente malgré l'entrée au répertoire de la Comédie-Française en 1918, les tentatives de Jean Vilar dans les années 1950, de Bernard Jenny en 1964, de Fabio Pacchioni en 1975, enfin d'Antoine Vitez au festival de Venise en 1985, puis à Avignon, Athènes et Belgrade; l'adaptation en opéra par Felice Romani pour Donizetti et les films du xxe (en fait plus larges que véritablement inspirés du drame hugolien) ne semblent rien avoir changé à cet oubli que la présente édition pourra peut-être aider à conjurer en rendant l'accès au texte facile à un large lectorat comme à des troupes éventuellement intéressées. 